\title{
Gallotannins from Nut Shell Extractives of Camellia oleifera ${ }^{1}$
}

\author{
Yi-Chang $\mathrm{HE}^{2,3} \cdot$ Mei-Jie $\mathrm{WU}^{3} \cdot \mathrm{Xiao}-\mathrm{Lin} \mathrm{LEI}^{3} \cdot \mathrm{Jie}-\mathrm{Fang} \mathrm{YANG}^{3} \cdot \mathrm{Wei} \mathrm{GAO}^{3} \cdot$ \\ Young-Soo $\mathrm{BAE}^{3,5} \cdot$ Tae-Hee $\mathrm{KIM}^{4} \cdot$ Sun-Eun $\mathrm{CHOI}{ }^{4, \dagger} \cdot$ Bao-Tong $\mathrm{LI}\left(^{2, \dagger}\right.$
}

\begin{abstract}
Camellia nut shell was collected, dried at room temperature and ground to get fine powder. The powder was extracted three times with $95 \% \mathrm{EtOH}$, combined, evaporated, and then freeze dried. The crude powder was dissolved in $\mathrm{H}_{2} \mathrm{O}$ and then sequentially fractionated with $n$-hexane, $\mathrm{CH}_{2} \mathrm{Cl}_{2}$, EtOAc and $n$-BuOH. A part of EtOAc fraction was chromatographed on a silica gel and on a Sephadex LH-20 columns using MeOH, aqueous MeOH, EtOAc- $n$-hexane and EtOH- $n$-hexane to isolate gallotannins. Three gallotannins, 1,2-di- $O$-galloyl- $\beta$-D-glucopyranoside $(2)$, 1,2,6-tri- $O$ galloyl- $\beta$-D-glucopyranoside (3) and 1,2,3,6-tetra- $O$-galloyl- $\beta$-D-glucopyranoside (4), including gallic acid (1), were isolated and elucidated by NMR and Mass spectroscopies. Although nothing new, these gallotannins were first reported from the nut shell extractives of camellia tree (Camellia oleifera $\mathrm{C}$. Abel). This study was to investigate the chemical constituents, especially hydrolysable tannins, of nut shell extractives of Camellia oleifera and to provide basic information for the future chemical utilization of this species.
\end{abstract}

Keywords: Camellia oleifera, ${ }^{13} \mathrm{C}-\mathrm{NMR},{ }^{1} \mathrm{H}-\mathrm{NMR}$, FAB-MS, gallotannin

\section{INTRODUCTION}

The camellia is valued not only for its aesthetic contribution as an ornamental tree or shrub but also for its economic importance as it provides the beverage, tea, and edible oil in some countries, notably China (Rolfe, 1992). Apart from its use for ornamental purposes and production of tea, camellia is one of the four main oil-bearing trees (palm, coconut, olive, and tea) in the world (Anon, 2007).

Camellia oleifera C. Abel, which originated in southern China, is notable as an important source of edible oil obtained from its seeds. It is commonly known as the oil-seed camellia or tea oil camellia, though to a lesser extent other species of camellia are used in oil production too. One of the other tea trees, Camellia japon$i c a$, is distributed in Korea, China, Taiwan, and Japan.

Previous studies have revealed that Camellia olei-

${ }^{1}$ Date Received March 11, 2021, Date Accepted May 18, 2021

${ }^{2}$ College of Land Resources and Environment, Jiangxi Agricultural University, Key Lab of Agricultural Resources and Ecology of Poyang Lake Basin, Nanchang 330045, Jiangxi Province, China

3 Jiangxi Academy of Forestry, Nanchang 330032, Jiangxi Province, China

${ }^{4}$ Department of Forest Biomaterials Engineering, College of Forest \& Environmental Sciences, Kangwon National University, Chuncheon 24341, Republic of Korea

${ }^{5}$ Kangwon National University, Chuncheon 24341, Republic of Korea

$\dagger$ Corresponding author: Sun-Eun CHOI (e-mail: oregonin@kangwon.ac.kr, ORCID: 0000-0002-6306-0372)

$\dagger$ Corresponding author: Bao-Tong LI (e-mail: libt66@163.com, ORCID: 0000-0002-9435-4509) 
Yi-Chang $\mathrm{HE} \cdot$ Mei-Jie WU $\cdot$ Xiao-Lin LEI $\cdot$ Jie-Fang YANG $\cdot$ Wei GAO $\cdot$ Young-Soo BAE $\cdot$ Tae-Hee KIM $\cdot$ Sun-Eun CHOI $\cdot$ Bao-Tong LI

fera has significant biological activities and includes various kinds of chemical constituents such as terpenoids and flavonoids in its leaves, roots, seeds and fruit shells (Xiong et al., 2018). Also Luan et al. (2020) has reported on the recent advances in Camellia oleifera $\mathrm{C}$. Abel through a review of nutritional constituents, bio-functional properties, and potential industrial applications.

But there is a very little study on the camellia nut shell extractives even in China.

Several researches have previously reported a couple of papers on the isolation and structure determination of gallotannins from domestic tree species (Kwon and Bae, 2009; Lee and Bae, 2015; Lee et al., 2016a; Lee et al., 2016b).

Recently some domestic researchers also have evaluated on the biological activities of pine and oak tree species (Masendra et al., 2019; Mun et al., 2020; Mun et al., 2021; Jung et al., 2017; Yang et al., 2019; Min et al., 2019; Manurung et al., 2019).

However, there was no chemical constituent study on the species, including domestic camellia tree (Camellia japonica) extractives, although several papers have reported on the antioxidative and anti-inflammatory activities.

Furthermore, there is no research at all on the chemical constituent of camellia nut shell which is one of agricultural waste.

Therefore, this study was to investigate the chemical constituents, especially hydrolysable tannins, of nut shell extractives of Chinese Camellia oleifera, to promote international cooperative research between countries on wood extractives study and to provide basic information for the utilization of domestic camellia extractives in the future through this study.

\section{MATERIALS and METHODS}

\subsection{Materials}

The nut shell of camellia tree (Camellia oleifera) was obtained from Fenyi county Camellia Oil Company in Xinyu, Jiangxi Province, China. The materials were air-dried at room temperature for 2 weeks and ground (150-200 mesh).

\subsection{General experiment}

${ }^{1} \mathrm{H}$ and ${ }^{13} \mathrm{C}$ NMR spectra were recorded on a Bruker Avance DPX $400 \mathrm{MHz}$ spectrometer using tetramethylsilane (TMS) as an internal standard, and chemical shifts are given in $\delta$ (ppm). FAB-MS was conducted using an Autospec M363 spectrometer (Micromass, Manchester, UK). Column chromatography was done on a lipophilic Sephadex LH-20 (25-100 um, sigma) and silica gel (230-400 mesh, sigma) columns. Eluents were collected using a fraction collector (Gilson, FC 204). Thin layer chromatography (TLC) was performed on DC-Plastikfolien Cellulose F (Merck) plates and developed with TBAW ( $t$-BuOH-HOAc- $\mathrm{H}_{2} \mathrm{O}, 3: 1: 1$, $\mathrm{v} / \mathrm{v} / \mathrm{v}$ ) and $6 \%$ aqueous HOAc. Visualization was done under UV light (254 and $365 \mathrm{~nm}$ ) followed by heating after spray of vanillin- $\mathrm{HCl}$ (vanillin: $\mathrm{HCl}: \mathrm{EtOH}, 4.8: 12: 480$ $(\mathrm{w} / \mathrm{v} / \mathrm{v}))$ solution.

\subsection{Extraction and Isolation}

The air-dried, ground nut shell of camellia tree (20 $\mathrm{kg}$ ) was immersed in $95 \% \mathrm{EtOH}$ at room temperature for 3-5 days. After filtration, above extraction was repeated 3 times. The filtrates were combined together and concentrated on a rotary evaporator under the reduced pressure at $40{ }^{\circ} \mathrm{C}$. The aqueous residue $(260 \mathrm{~g})$ was successively fractionated on a separatory funnel and freeze dried to give $n$-hexane (29 g), $\mathrm{CH}_{2} \mathrm{Cl}_{2}(24$ g), EtOAc (63 g), n-BuOH (21 g) and $\mathrm{H}_{2} \mathrm{O}(136 \mathrm{~g})$ soluble fractions.

A portion of EtOAc fraction (28 g) was chromatographed on a silica gel column using EtOAc : $n$-hexane mixtures $(1: 3 \longrightarrow 1: 1 \rightarrow 2: 1)$ as eluting solvents to afford 8 fractions: EF-1 (4.6 g), EF-2 (1.4 g), EF-3 
(0.8 g), EF-4 (2.7 g), EF-5 (3.1 g), EF-6 (2.3 g), EF-7 $(2.8 \mathrm{~g})$ and EF-8 (2.7 g). EF-2 was retreated on a Sephadex LH-20 column with $\mathrm{MeOH}-\mathrm{H}_{2} \mathrm{O}$ mixtures $(1: 1 \rightarrow 1: 3)$ to isolate compound 1 (0.72 g). EF-4 was also rewashed on a Sephadex LH-20 using $\mathrm{MeOH}-$ $\mathrm{H}_{2} \mathrm{O}$ (1:4) followed by EtOH: $n$-hexane (2:1) and then $\mathrm{MeOH}-\mathrm{H}_{2} \mathrm{O}(3: 1)$ to give $78 \mathrm{mg}$ of compound 2. EF-6 was also rechromatographed on a Sephadex LH-20 using $\mathrm{MeOH}-\mathrm{H}_{2} \mathrm{O}(1: 3 \rightarrow 1: 1 \rightarrow 2: 1)$ and finally with $100 \%$ methanol to get compound 4 (93 mg). EF-8 was washed again on a Sephadex LH-20 using $\mathrm{MeOH}-\mathrm{H}_{2} \mathrm{O}$ mixtures $(1: 3 \rightarrow 1: 1 \rightarrow 2: 1 \rightarrow 100 \% \mathrm{MeOH})$ and finally with $\mathrm{MeOH}-\mathrm{H}_{2} \mathrm{O}$ (3:1) to afford compound 3 (134 mg).

\subsubsection{Compound 1}

Brown amorphous powder, $\mathrm{R}_{\mathrm{f}} 0.54$ (TBAW) and 0.41 (6\% HOAc), FAB-MS: calculated for $\mathrm{C}_{7} \mathrm{H}_{6} \mathrm{O}_{5}$, 170, found $m / z 171[\mathrm{M}+\mathrm{H}]^{+}$, ${ }^{1} \mathrm{H}-\mathrm{NMR}\left(\mathrm{MeOH}-d_{4}\right): 7.1$ $(2 \mathrm{H}, s, \mathrm{H}-2,6) .{ }^{13} \mathrm{C}-\mathrm{NMR}\left(\left(\mathrm{MeOH}-d_{4}\right): 109.9(\mathrm{C}-2,6)\right.$, 122.4 (C-1), 138.6 (C-4), 145.8 (C-3, 5), 170.8 (C-7).

\subsubsection{Compound 2}

Brown amorphous powder, $\mathrm{R}_{\mathrm{f}:} 0.38$ (TBAW) and 0.33 (6\% HOAc), FAB-MS: calculated for $\mathrm{C}_{20} \mathrm{H}_{20} \mathrm{O}_{14}$, 484, found $m / z 485[\mathrm{M}+\mathrm{H}]^{+}$. ${ }^{1} \mathrm{H}-\mathrm{NMR}\left(\mathrm{MeOH}-d_{4}\right)$ : 3.54-3.74 (2H, H-4, 5), $4.36(1 \mathrm{H}, d d, J=5,12 \mathrm{hz}$, glu $\mathrm{H}-6), 4.60(1 \mathrm{H}, d d, J=2,12 \mathrm{hz}$, glu H-6), $5.15(2 \mathrm{H}$, glu H-2, 3), $5.71(1 \mathrm{H}, d, J=8 H z$ glu H-1), 7.12, 7.16 (each $2 \mathrm{H}, S$, galloyl $\mathrm{H}-2,6) .{ }^{13} \mathrm{C}-\mathrm{NMR}\left(\left(\mathrm{MeOH}-d_{4}\right)\right.$ : 95.4 (glu C-1), 73.2 (glu C-2), 77.0 (glu C-3), 70.6 (glu C-4), 75.5 (glu C-5), 64.3 (glu C-6), 120.1, 120.9 (galloyl C-1), 110.0, 110.3 (each 2C, galloyl C-2, 6), 145.8 (4C, galloyl C-3, 5), 139.1, 139.5 (galloyl C-4), 166.3, 166.5 (galloyl $\mathrm{C}=\mathrm{O}$ ).

\subsubsection{Compound 3}

White brown amorphous powder, $\mathrm{R}_{\mathrm{f}:} 0.25$ (TBAW) and 0.10 (6\% HOAc), FAB-MS: calculated for $\mathrm{C}_{27} \mathrm{H}_{24} \mathrm{O}_{18}, 636$, found $m / z 637[\mathrm{M}+\mathrm{H}]^{+}$. ${ }^{1} \mathrm{H}-\mathrm{NMR}$
(MeOH- $\left.d_{4}\right): 3.67-3.85(2 \mathrm{H}, d d$, glu H-4, 5), $4.48(1 \mathrm{H}$, $d d, J=5,12 \mathrm{hz}$, glu H-6), $4.58(1 \mathrm{H}$, br $d, J=12 \mathrm{hz}$, glu H-6), $5.24(2 \mathrm{H}, t, \mathrm{~J}=9 \mathrm{~Hz}$, glu H-2, 3), $5.93(1 \mathrm{H}$, $d, J=8 \mathrm{~Hz}$, glu H-1), 7.04, 7.08, 7.15 (each $2 \mathrm{H}, s$, galloyl H-2, 6). ${ }^{13} \mathrm{C}-\mathrm{NMR}$ ((MeOH- $\left.d_{4}\right): 94.1$ (glu C-1), 74.3 (glu C-2), 75.9 (glu C-3), 71.4 (glu C-4), 76.6 (glu C-5), 64.2 (glu C-6), 120.1, 121.1, 121.3 (galloyl C-1), 110.3, 110.5, 110.6 (each 2C, galloyl C-2, 6), 146.4 (6C, galloyl C-3, 5), 138.8, 139.0, 139.5 (galloyl C-4), 166.5, 167.6, 168.3 (galloyl C=O).

\subsubsection{Compound 4}

White brown amorphous powder, $\mathrm{R}_{\mathrm{f}:} 0.16$ (TBAW), 0.19 (6\% HOAc), FAB-MS: calculated for $\mathrm{C}_{34} \mathrm{H}_{28} \mathrm{O}_{22}$, 788, found $m / z 789[\mathrm{M}+\mathrm{H}]^{+}$. ${ }^{1} \mathrm{H}-\mathrm{NMR}\left(\mathrm{MeOH}-d_{4}\right)$ : $4.54(1 \mathrm{H}, d d, J=5,12 \mathrm{hz}$, glu H-6), $4.63(1 \mathrm{H}, d d, J=$ $12 \mathrm{hz}$, glu H-6), $6.12(1 \mathrm{H}, d, J=8 \mathrm{~Hz}$, glu H-1), 5.60 $(1 \mathrm{H}, d d, J=8 H z$, glu $\mathrm{H}-3), 5.46(1 \mathrm{H}, d d, J=8 H z$, glu $\mathrm{H}-2), 3.98-4.03$ (2H, $m, J=8 H z$, glu H-4, 5), 6.95, 7.03, $7.05,7,14$ (each $2 \mathrm{H}, s$, galloyl $\mathrm{H}-2,6$ ). ${ }^{13} \mathrm{C}-\mathrm{NMR}$ (MeOH- $d_{4}$ ): 93.8 (glu C-1), 72.3 (glu C-2), 76.4 (glu C-3), 79.6 (glu C-4), 76.5 (glu C-5), 63.9 (glu C-6), 119.8, 120.4, 120.9, 121.2 (galloyl C-1), 110.2, 110.4, 110.5, 110.6 (each 2C, galloyl C-2, 6), 146.3-146.6 (8C, galloyl C-3, 5), 139.9-140.6 (4C, galloyl C-4), 166.3, 167.1, 167.7, 168.1 (4C, galloyl $\mathrm{C}=\mathrm{O})$.

\section{RESULTS and DISCUSSION}

\subsection{Compound 1}

Compound 1 was obtained as a brownish amorphous powder from the EtOAc soluble fraction. The molecular formula of $\mathrm{C}_{7} \mathrm{H}_{6} \mathrm{O}_{5}$ was supported by an ion peak at $m / z 171[\mathrm{M}+\mathrm{H}]^{+}$in the FAB-MS spectrum. ${ }^{1} \mathrm{H}-\mathrm{NMR}$ gave one signal at $\delta \quad 7.1$, indicating a pair of symmetrical galloyl protons, H-2 and H-6. ${ }^{13} \mathrm{C}-\mathrm{NMR}$ showed 7 carbon signals as already mentioned in 2.3.1. Therefore, compound 1 was identified as gallic acid (3,4,5-trihydroxy benzoic acid) (Luo et al., 2009; 
<smiles>O=C(O)c1cc(O)c(O)c(O)c1</smiles>

(1)<smiles>O=C(OC[C@H]1O[C@@H](OC(=O)c2cc(O)c(O)c(O)c2)[C@H](OC(=O)c2cc(O)c(O)c(O)c2)[C@H](O)[C@@H]1O)c1cc(O)c(O)c(O)c1</smiles>

(3)

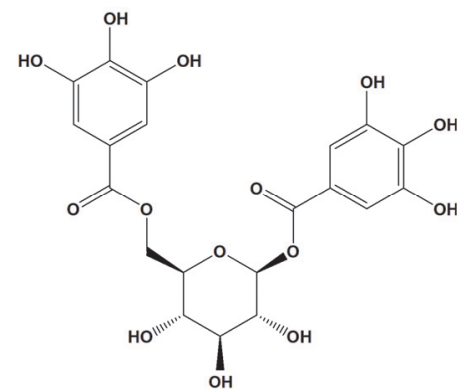

(2)<smiles>O=C(OC[C@H]1O[C@@H](OC(=O)c2cc(O)c(O)c(O)c2)[C@H](O)[C@H](OC(=O)c2cc(O)c(O)c(O)c2)[C@@H]1OC(=O)c1cc(O)c(O)c(O)c1)c1cc(O)c(O)c(O)c1</smiles>

(4)

Fig. 1. Compounds from nut shell extractives of Camellia oleifera.

Kashiwada et al. 1988; Saijo et al., 1990).

\subsection{Compound 2}

Compound 2 was brown amorphous powder and contains two galloyl groups as indicated by the ${ }^{1} \mathrm{H}-\mathrm{NMR}$ and ${ }^{13} \mathrm{C}-\mathrm{NMR}$ spectra. In the ${ }^{1} \mathrm{H}-\mathrm{NMR}$ spectrum, compound $\mathbf{2}$ appeared the doublet anomeric proton signal shifted considerably downfield at $\delta \quad 5.71$ $(J=8 \mathrm{~Hz})$, indicating that the galloyl is connected to this position through an ester linkage and with $\beta$ mode. Another galloyl was concluded to be present at the glucose C- 6 position by the significantly deshielded signals, attributable to the glucose two H-6 ( $\delta 4.36$ and $\delta 4.60, d d$ ) signals and clear different from other sugar signals.

The ${ }^{13} \mathrm{C}$-NMR spectrum showed the typical glucose signals, including C-1 at 95.4 ppm and C-6 at 64.3 ppm. The galloyl carbonyls gave 2 signals at 166.3 and $166.5 \mathrm{ppm}$. Two pairs of symmetric carbons indicated at 110 and $110.3 \mathrm{ppm}$ (4C, C-2 and C-6) and at $145.8 \mathrm{ppm}$ (4C, C-3 and C-5), respectively.

Above NMR data were similar to the previous reported literatures (Tanaka et al., 1982; Nonaka and Nishioka, 1983; Li et al., 2015) and the compound was determined as 1,2-di-O-galloyl- $\beta$-D-glucopyranoside.

\subsection{Compound 3}

Compound 3 was white brown amorphous powder 
and contains three galloyl groups as appeared by the ${ }^{1} \mathrm{H}$ - and ${ }^{13} \mathrm{C}-\mathrm{NMR}$ data.

The ${ }^{1} \mathrm{H}-\mathrm{NMR}$ spectrum showed three symmetric galloyl group signals at $\delta 7.04, \delta 7.08$ and $\delta 7.15$ (each $2 \mathrm{H}$ ) and also six signals of the glucose moiety at $\delta \quad 6.93(\mathrm{H}-1), \delta \quad 5.24(\mathrm{H}-2, \mathrm{H}-3), \delta \quad 4.48-4.58$ (H-6), and $\delta$ 3.67-3.85 (H-4, 5). The location of the three galloyl in the glucose moiety were decided to be the C-1, C- 2 and C- 6 by the analysis of the ${ }^{13} \mathrm{C}$-NMR data that was notable for the deshielding of the corresponding $\mathrm{H}-1$ ( $\delta$ 5.93, $d, J=8.4 \mathrm{~Hz}$ ), H-2 ( $\delta$ $5.24, t, J=9.1 \mathrm{~Hz}$ ) and H-6 ( $\delta$ 4.48-4.58, $d d, J=4,12$ $\mathrm{Hz}$ ), being assignable to the protons germinal to gallo$\mathrm{yl}$ groups.

The ${ }^{13} \mathrm{C}$-NMR spectrum indicated six signals for the glucose moiety at 64.2-94.1 ppm and three carbonyls of the galloyl groups at 166.5, 167.6 and $168.3 \mathrm{ppm}$. One three symmetric carbons gave three signals at $110.3,110.5$ and $110.6 \mathrm{ppm}$ for symmetric C-2 and C-6, respectively and another three symmetric carbons gave the signals at $146.3-146.4 \mathrm{ppm}$ for symmetric $\mathrm{C}-3$ and $\mathrm{C}-5$.

These NMR spectra were identical to the report by Nonaka et. al. (1981) and compound 3 was elucidated to 1,2,6-tri-O-galloyl- $\beta$-D-glucopyranoside.

\subsection{Compound 4}

Compound 4 was isolated as a yellowish amorphous powder from the EtOAc soluble fraction of camellia nut shell extractive. The molecular formula of $\mathrm{C}_{34} \mathrm{H}_{28} \mathrm{O}_{22}$ was supported by an ion peak at $m / z 788[\mathrm{M}+\mathrm{H}]^{+}$in the FAB-MS spectrum.

In ${ }^{1} \mathrm{H}-\mathrm{NMR}$ spectrum, anomeric proton $\mathrm{H}-1$ containing one galloyl group gave a doublet signal at $\delta 6.12$, indicating $\beta$-structure with $J=8.2 \mathrm{~Hz}$. The other galloyl containing $\mathrm{H}-2$ and $\mathrm{H}-3$ appeared at $\delta 5.46$ and $\delta 5.60$, respectively. The fourth galloyl containing H-6 gave two double doublet signals at $\delta 4.54$ and $\delta$ 4.63 .
These ${ }^{1} \mathrm{H}-\mathrm{NMR}$ spectra were identical to the literature (Duan et al., 2004; Owen et al., 2003; Saijo et al., 1989).

In ${ }^{13} \mathrm{C}-\mathrm{NMR}$ spectrum, six carbons of the glucose unit resonated at 63.9-93.8 ppm. Anomeric C-1 gave a signal at $93.8 \mathrm{ppm}$ and $\mathrm{C}-6$ appeared at $63.9 \mathrm{ppm}$. Four carbonyls of the galloyl groups showed four signals at 166.3-168.1 ppm. One four pairs of symmetric carbons (C-2 and C-6) gave the signals at 110.2-110.6 ppm and another four pairs of symmetric carbons (C-3 and C-5) showed four signals at 145.3-146.6 ppm. These ${ }^{13} \mathrm{C}-\mathrm{NMR}$ data were the same as the previous reported data (Duan et al., 2004; Owen et al., 2003; Cui et al., 2002; Lee, 2016).

Therefore, this compound was identified as $1,2,3,6$ tetra- $O$-galloyl- $\beta$-D-glucopyranoside.

In general, gallotannins are reported to have excellent biological activities such as antioxidation and antiinflammation, and it will be necessary to evaluate the biochemical properties on the isolated compounds for the chemical application in the future.

\section{CONCLUSIONS}

Three gallotannins, 1,2-di- $O$-galloyl- $\beta$-D-glucopyranoside (2), 1,2,6-tri- $O$-galloyl- $\beta$-D-glucopyranoside (3) and 1,2,3,6-tetra- $O$-galloyl- $\beta$-D-glucopyranoside (4), including gallic acid (1), were isolated from the EtOAC fraction of the nut shell extractives of Camellia oleifera. The isolation was done by column chromatography using silica gel and Sephadex LH-20 as column packing gels. The column washing solvents were $\mathrm{MeOH}$, aqueous $\mathrm{MeOH}$ and $\mathrm{EtOH}-n$-hexane. Structure determination was done by NMR and FAB-MS spectroscopy. Although nothing new, these gallotannins were first reported from the nut shell extractives of Camellia oleifera $\mathrm{C}$. Abel. Then it will be necessary to evaluate the biochemical properties on the isolated compounds for future use. 
Yi-Chang HE $\cdot$ Mei-Jie WU $\cdot$ Xiao-Lin LEI $\cdot$ Jie-Fang YANG $\cdot$ Wei GAO $\cdot$ Young-Soo BAE $\cdot$ Tae-Hee KIM $\cdot$ Sun-Eun CHOI $\cdot$ Bao-Tong LI

\section{ACKNOWLEDGMENT}

This study was supported by "R\&D Program for Forest Science Technology (Project No. 2019151D102023-0301) of Korea Forest Service and also by Science and Technology Innovation Project of Forestry Department of Jiangxi Province (No. 201809) and also partially supported by Key Science and Technology Project of Jiangxi Academy of Forestry (No. 2018512101).

\section{REFERENCES}

Anon. 2007. International Plant Nutrition Institute, Oil-Tea and Its Production. p. 313.

Cui, C.B., Zhao, Q.C., Cai, B., Yao, X.S., Osadsa, H. 2002. Two new and four known polyphenolics obtained as new cell-cycle inhibitors from Rubus aleaefolius Poir. Journal of Asian Natural Products Research 4(4): 243-252.

Duan, D., Li, Z., Luo, H., Zhang, W., Chen, L., Xu, X. 2004. Antiviral compounds from traditional Chinese medicines Galla Chinese as inhibitors of HCV NS3 protease. Bioorganic \& Medicinal Chemistry Letters 14(24): 6041-6044.

Jung, J.Y., Ha, S.Y., Yang, J.K. 2017. Response surface optimization of phenolic compounds extraction from steam exploded oak wood (Quercus mongolica). Journal of the Korean Wood Science and Technology 45(6): 809-827.

Kashiwada, Y., Nonaka, G.I., Nishioka, I. 1988. Galloylglucose from Rhubarbs. Phytochemistry 27: 1469-1472.

Kwon, D.J., Bae, Y.S. 2009. Ellagitannins from bark of Juglans mandshurica. Journal of the Korean Wood Science and Technology 37(5): 480-485.

Lee, T.S., Bae, Y.S. 2015. A gallotannin from Cercidiphyllum japonicum leaves. Journal of the Korean Wood Science and Technology 43(5): 558-565.
Lee, M.S., Min, H.J., Kim, J.K., Bae, Y.S. 2016a. A polyoxygenated ellagitannin from Cercidiphyllum japonicum bark. Journal of the Korean Wood Science and Technology 44(4): 551-558.

Lee, M.S., Min, H.J., Si, C.L., Bae, Y.S. 2016b. Hydrolysable tannins from Cercidiphyllum japonicum Bark. Journal of the Korean Wood Science and Technology 44(4): 559-570.

Lee, M.S. 2016. Hydrolysable tannins of katsura tree bark. Master's thesis, p. 29-30.

Li, C.W., Dong, H.J., Cui, C.B. 2015. The synthesis and antitumor activity of twelve galloyl glucosides. Molecules 20(2): 2034-2060.

Luan, F., Zeng, J., Yang, Y., He, X., Wang, B., Gao, Y., Zeng, N. 2020. Recent advances in Camellia oleifera C. Abel: A review of nutritional constituents, bio-functional properties, and potential industrial applications. Journal of Functional Food 75: 104-242.

Luo, W., Zhao, M., Yang, B., Shen, G., Rao, G. 2009. Identification of bioactive compounds in Phyllenthus emblica $\mathrm{L}$. fruit and their free radical scavenging activities. Food Chemistry 114(2): 499-504.

Manurung, H., Sari, R. K., Syafii, W., Cahyaningsih, U., Ekasari, W. 2019. Antimalarial activity and phytochemical profile of ethanolic and aqueous extracts of Bidara laut (Strychnos ligustrina Blum) Wood. Journal of the Korean Wood Science and Technology 47(5): 587-596.

Masendra, M., Ashitani, T., Takahashi, K., Susanto, M., Lukmandaru, G. 2019. Hydrophilic extracts of the bark from six Pinus species. Journal of the Korean Wood Science and Technology 47(1): 80-89.

Min, H.J., Kim, E.J., Shinn, S.W., Bae, Y.S. 2019. Antidiabetic Activities of Korean Red Pine (Pinus densiflora) Inner Bark Extracts. Journal of the Korean Wood Science and Technology 47(4): 498-508.

Mun, J.S., Kim, H.C., Mun, S.P. 2020. Chemical 
Characterization of Neutral Extracts Prepared by Treating Pinus radiata Bark with Sodium Bicarbonate. Journal of the Korean Wood Science and Technology 48(6): 878-887.

Mun, J.S., Kim, H.C., Mun, S.P. 2021. Potential of Neutral Extract Prepared by Treating Pinus radiata Bark with $\mathrm{NaHCO}_{3}$ as a Dyestuff. Journal of the Korean Wood Science and Technology 49(2): 134-141.

Nonaka, G., Nishioka, I., Nagasawa, T., Oura, H. 1981. Tannins and related compounds. I. Rhubarb (1). Chemical and Pharmaceutical Bulletin 29(10): 2862-2870.

Nonaka, G.I., Nishioka, I. 1983. Tannins and related compounds. X. Rhubarb (2): Isolation and structures of a glycerol gallate, gallic acid glucoside gallates, galloylglucoses and isolindleyin. Chemical and Pharmaceutical Bulletin 31(5): 1652-1658.

Owen, R. W., Haubner, R., Hull, W.E., Erben, G., Spiegelhalder, B., Bartsch, H., Haber, B. 2003.
Isolation and structure elucidation of the major individual polyphenols in carob fiber. Food and Chemical Toxicology 41(12): 1727-1738.

Rolfe, J. 1992. Gardening with Camellias: A Complete Guide. Kangaroo Press: Kenthurst, NSW.

Saijo, R., Nonaka, G. I., Nishioka, I. 1990. Gallic acid esters of bergenin and norbergenin from Mallotus japonicus. Phytochemistry 29(1): 267-270.

Tanaka, L.T., Nonaka, G.I., Nishioka, I. 1982. Abstracts of papers, $28^{\text {th }}$ annual meeting of the Japanese society of pharmacognosy. Sapporo, Sept, p. 48.

Xiong, W., Fu, J.P., Hu, J.W., Wang, H.B., Han, X.D., $\mathrm{Wu}, \mathrm{L} .2018$. Secondary metabolites from the fruit shells of Camellia oleifera. Chemistry of Natural Compounds 54(6): 1189-1191.

Yang, J., Choi, W.S., Kim, J.W., Lee, S.S., Park, M.J. 2019. Anti-Inflammatory Effect of Essential Oils Extracted from Wood of Four Coniferous Tree Species. Journal of the Korean Wood Science and Technology 47(6): 674-691. 